\title{
Work quality and standards of small and medium enterprises in the agro-industrial and construction business in Thailand
}

\author{
Pisit Potjanajaruwit ${ }^{1, *}$ \\ ${ }^{1}$ FMS, Suan Sunandha Rajabhat University, 1 U-Thong Nok rd, 10200, Dusit, Bangkok, Thailand
}

\begin{abstract}
The purpose of this research was to study the factors that influence the decision of Small and Medium Enterprise (SMEs) in the Northeast region of Thailand to use loan services from Kasikorn Bank. The population in this research was 1,746 SMEs entrepreneurs who used loan services for Small and Medium Enterprise customers provided by Kasikorn Bank Public Company Limited in the North-eastern region of Thailand. Multi-stage Cluster Sampling was used in sampling 325 SMEs entrepreneurs and a 5 rating-scale questionnaire was used as a research tool, with the confidence value of independent variables of .96 and the confidence value of dependent variables of .83 . The statistics used in analysis were Frequency, Percentage, Mean, Standard Deviation, Multiple Regression Analysis, T-test, and F-test. 7 factors were found to have influence in the decision to use loan services of the Small and Medium Enterprises customers at a high level. These following factors are listed in order from highest to lowest average scores; Service Process, Physical Evidence and Presentation, Personnel, Products, Distribution, Marketing Promotion, and Price. Only 2 factors were found to have an influence on the customers' decision to use loan services with standardized coefficient of determination for multiple regression at the significance level of .01; Service Process $($ Beta $=.43)$ and Personnel $($ Beta $=.19)$ and both factors together could be used to determine $35 \%$ of dependent variables with statistical significance.
\end{abstract}

\section{Introduction}

In the modern world, commercial banks are financial institutions that play major and important roles in the country's financial system as they are the largest source for savings and loans. The commercial banks also play a role in determining the money usage system, in increasing or decreasing financial input in the system, and in responding to state financial policies. Therefore, for the country's economy to grow and progress, commercial banks are necessary to provide financial assistance and to support the public and private sectors [1]. The impact of Thailand's financial crisis in 1997 and the rapid changes in modern technology in the world today, together with highly-volatile factors in the domestic economy such as high fuel prices, political instability, natural disasters, or the spread of

*Corresponding author: Pisit.po@ssru.ac.th 
pandemics or epidemics, result in intensifying competition in the domestic banking business. In order to keep up with the changing business situation, commercial banks in Thailand change and adjust their organization's management. Several banks focus on providing a wide range of services as fast and as much as possible to meet the needs of customers.

The banks also attempt to increase their market share in order to expand the revenue base and to control costs to increase their profitability, especially in providing loans for Small and Medium Enterprises (SMEs). According to the Office of Industrial Economics, production units in the domestic industry sector consist of more than $90 \%$ of Small and Medium Enterprises (SMEs) out of the production units in the industrial sector of the whole country. These small and medium production units have higher production flexibility or agility in production process than large businesses and rely on smaller funds. Therefore, these businesses are also an opportunity for new entrepreneurs with work experience who plan to run their own business [2].

In addition, competitions in loan services of the commercial banks in Thailand have also become more intense which can be seen from the fact that various commercial banks have adopted marketing strategies as a means to expand the target customer group. However, there are now very in-depth studies that bring the results of marketing research into the design of various financial products and services that are comprehensive. This also can be used to adjust the banks' working process to be more efficient and be able to meet the needs of Small and Medium Enterprises (SMEs) customers as much as possible. Therefore, the study of factors affecting the decision to use loan services of Small and Medium Enterprises in the northeast region of Thailand is very important as it helps commercial banks to be more aware of factors that affect the decision to use loan services of the Small and Medium Enterprises (SMEs) customer group, which can further lead to the formulation of a competitive and effective strategy for loan services.

Kasikorn Bank Public Company Limited was established on 8th June 2488 with a registered capital of 5 million baht and only 21 employees at the start. The first branch used a building that is now currently their Sue Pa Branch. However, the operation of the bank has been so successful that it is now classified as the largest commercial bank in the country according to the ranking of the Bank of Thailand.

The main business operations deal with all types of commercial banking as specified in the Commercial Banking Act and its related announcements. In addition, they also do other government-licensed businesses such as provision of financial consultants and bondassociated businesses. Additionally, the bank also emphasizes responding to the needs of each customer group with high-quality financial products and services by adhering to customer centricity and creating "K Now" which is a source of knowledge on financial services under their new philosophy of "KASIKORNBANK GROUP: A People to Simplify your Life". The bank also aims to be the best service provider in all 6 types of businesses (1 Brand 6 Companies) under the operation of Kasikorn Bank Group [3].

From the reasons mentioned above, it can be seen that studying the factors affecting the decision to use loan services of Small and Medium Enterprises (SMEs) in the northeast region of Thailand is absolutely necessary. The objective of this research is determining the factors with influence on the decision to use credit services from Kasikorn Bank of Small and Medium Enterprises (SMEs) customers in the north-eastern region of Thailand.

\section{Methodology}

In the research "Decision-making on Loan Services of Small and Medium Enterprises (SMEs) In the North-eastern region of Thailand", methods of study and research are 
determined as follows; 1. Population, 2. Sample Group, 3. Data Collection Tools, 4. Data collection and 5. Statistics used for data analysis.

\subsection{Determination of population}

The population used in the research consisted of 1,746 Small and Medium Enterprise (SMEs) entrepreneurs who used loan services with Kasikorn Bank Public Company Limited at their North-eastern regional branches, such as Thanon Phromthep (Ubon Ratchathani Province), Thanon Chayangkoon (Amnat Charoen Province), Chamrap (Yasothon Province), Phimai (Nakhon Ratchasima Province), and Dejkamjorn (Buri Ram Province) as based on the information as of 31st December 2019 [2].

\subsection{The process of specifying samples}

The researcher selected the sample group (Sampling) by stratified random sampling method. (Proportional Stratified Random Sampling) is divided into samples used for analysis and improvement of the test as follows.

Table 1. Number of customers using the loan services of Kasikorn Bank Public Company Limited in the Northeastern region as sorted according to branches' name and location. Data is from Kasikorn

Bank Public Company Limited [2].

\begin{tabular}{|c|c|}
\hline Branch of Kasikorn Bank & Number of customers \\
\hline Thanon Phromthep (Ubon Ratchathani Province) & 402 \\
\hline Thanon Chayangkoon (Amnat Charoen Province) & 677 \\
\hline Chamrap (Yasothon Province) & 283 \\
\hline Phimai (Nakhon Ratchasima Province) & 227 \\
\hline Dejkamjorn (Buri Ram Province) & 157 \\
\hline Total & 1,746 \\
\hline
\end{tabular}

The population was sampled. The sample size was determined using the comparison with the [4]. Referenced in [5]. and as a result, the number of 325 people was used.

Sample group as shown in Table 2

Table 2. Sample groups.

\begin{tabular}{|l|c|c|}
\hline \multicolumn{1}{|c|}{ Branch of Kasikorn Bank } & $\begin{array}{c}\text { Population } \\
\text { Size }\end{array}$ & $\begin{array}{c}\text { Sample } \\
\text { Size }\end{array}$ \\
\hline Thanon Phromthep (Ubon Ratchathani Province) & 402 & 75 \\
\hline Thanon Chayangkoon (Amnat Charoen Province) & 677 & 126 \\
\hline Chamrap (Yasothon Province) & 283 & 53 \\
\hline Phimai (Nakhon Ratchasima Province) & 227 & 42 \\
\hline Dejkamjorn (Buri Ram Province) & 157 & 29 \\
\hline \multicolumn{1}{|c|}{ Total } & $\mathbf{1 , 7 4 6}$ & $\mathbf{3 2 5}$ \\
\hline
\end{tabular}

After that, the samples were selected using Simple Random Sampling from the list of Small and Medium Enterprise (SMEs) customers who used loan services of Kasikorn Bank Public Company Limited in the north-eastern region according to the branch they used the service until reaching the desired number in the sample group.

\subsection{Creation of the study tool}

In this research, a questionnaire was used as a tool to gather data about the decision-making to use credit services of Small and Medium Enterprises (SMEs) in the northeastern region of Thailand. The questionnaire was created by studying the theories and other related study 
results covering the content and objective of the study. It was then used in a pre-test with a sample group of 50 samples to test its reliability and to find Cronbach's Alpha Coefficient. Discriminant Index was also determined using the relation between each question and the total results with the level of Discriminant Index set to be at the level of 0.80 and above. When the reliability of the entire questionnaire was found to be 0.96 , it was then qualified as a tool of good quality.

\subsection{Data collection}

Data was collected from Small and Medium Enterprises (SMEs) in the Northeastern region of Thailand who used the loan services of Kasikorn Bank Public Company Limited in 5 branches of in Northeastern region which were Thanon Phromthep (Ubon Ratchathani Province), Thanon Chayangkoon (Amnat Charoen Province), Chamrap, (Yasothon Province), Phimai (Nakhon Ratchasima Province), and Dejkamjorn (Buri Ram Province). The data was collected from 325 samples in person between 28th December 2019 and 31 st January 2020. The results revealed that all 325 questionnaires or $100 \%$ of them were returned and all 325 questionnaires, also $100 \%$, were completed.

\subsection{Data analysis and statistics used}

The data was analyzed by computer software using the statistics (Thong Bai Sudaree 2003: 187-217) as follows: 1. Percentage: used to analyze personal data, 2. Mean (X): used for classification and interpretation of variables, 3. Standard Deviation: used to show the distribution of data, 4. Multiple Regression was used to predict one dependent variable which results from two or more independent variables by using Enter and Stepwise Analysis with determined statistical significance at the level of .01

\section{Result}

Descriptive statistics were used to explore the factors affecting the decision to use loan services of Small and Medium Enterprises (SMEs) in the northeastern region of Thailand. It was found that respondents placed importance on the service mix in the part of Service Process at the high level ( $\bar{X}=4.13)$ which when considering the details of each item, it was found that every question was at a high value $(4.01<\bar{X}<4.25)$. The highest-rated answer was for the question if "the bank has always checked the accuracy of customer loans" ( $\bar{X}=4.25)$, followed by "the bank provides convenient service and is quick to approve loans" ( $\bar{X}=4.21)$.

Table 3. Mean and Standard Deviation of factors affecting the decision to use loan services of Small and Medium Enterprises (SMEs) in the Northeast region of Thailand.

\begin{tabular}{|l|c|c|c|}
\hline \multicolumn{1}{|c|}{ Factors affecting the decision to use loan } & $\overline{\mathbf{x}}$ & S.D & $\begin{array}{c}\text { Mean } \\
\text { Level }\end{array}$ \\
\hline $\begin{array}{l}\text { 1. The bank was accurate in recording the information } \\
\text { for loan applications. }\end{array}$ & 4.12 & 0.88 & High \\
\hline 2. The bank had an accurate and reliable system & 4.17 & 0.80 & High \\
\hline $\begin{array}{l}\text { 3. The bank always checked the accuracy of a customer's } \\
\text { loan application. }\end{array}$ & 4.25 & 0.76 & High \\
\hline $\begin{array}{l}\text { 4. The bank provided convenient service and were quick } \\
\text { to approve the loans. }\end{array}$ & 4.21 & 0.86 & High \\
\hline $\begin{array}{l}\text { 5. The bank managed loan applicators systematically and } \\
\text { appropriately. }\end{array}$ & 4.13 & 0.82 & High \\
\hline
\end{tabular}




\begin{tabular}{|l|c|c|c|}
\hline $\begin{array}{l}\text { 6. The bank's regulations and procedures in using services } \\
\text { were not too complicated. }\end{array}$ & 4.01 & 0.87 & High \\
\hline $\begin{array}{l}\text { 7. The bank's documents were clear and easy to } \\
\text { understand. }\end{array}$ & 4.07 & 0.90 & High \\
\hline $\begin{array}{c}\text { 8. The bank used modern equipment and up-to-date } \\
\text { technology (such as internet banking services) }\end{array}$ & 4.05 & 0.82 & High \\
\hline Total & $\mathbf{4 . 1 3}$ & $\mathbf{0 . 6 9}$ & High \\
\hline
\end{tabular}

From Multiple Regression Analysis using Ener Method, it was found that all 7 independent variables which were the Product Factors, Price Factors, Distribution Factors, Marketing Promotion Factors, Personnel Factors, Physical Evidence and Presentation Factors, and Service Process Factors had influence in predicting the decision to use loan services of Small and Medium Enterprises (SMEs) in the Northeast region of Thailand, representing 35.3\% (Adj R2 = .353).

Table 4. Multiple Regression Analysis of predicting the decision to use loan services of Small and Medium Enterprises (SMEs) in the Northeast region of Thailand.

\begin{tabular}{|c|c|c|c|c|c|}
\hline \multirow[t]{2}{*}{ Independent Variable } & \multicolumn{2}{|c|}{$\begin{array}{l}\text { Regression } \\
\text { Coefficient }\end{array}$} & \multirow[t]{2}{*}{$\mathbf{t}$} & \multirow[t]{2}{*}{$\mathbf{P}$} & \multirow[t]{2}{*}{ VIF } \\
\hline & b & Beta & & & \\
\hline Constant & 1.705 & & 7.509 & $.000^{* *}$ & \\
\hline Product & .085 & .079 & 1.223 & .222 & 2.084 \\
\hline Price & -.008 & -.008 & -.142 & .887 & 1.481 \\
\hline Distribution & .098 & .104 & 1.502 & .134 & 2.397 \\
\hline Promotion & -.032 & -.033 & -.407 & .684 & 3.304 \\
\hline Personnel & .185 & .244 & 2.803 & $.005^{* *}$ & 3.789 \\
\hline $\begin{array}{lll}\text { Physical } & \text { Evidence } & \text { and } \\
\text { Presentation } & & \\
\end{array}$ & -.043 & -.046 & -.682 & .496 & 2.302 \\
\hline Service Process & .273 & .328 & 3.352 & $.001^{* *}$ & 4.791 \\
\hline $\mathrm{R}=.606 \quad \mathrm{R}^{2}=.367 \quad \mathrm{~A}$ & $\mathrm{R}^{2}=.35$ & $\mathrm{SE}_{\text {est }}=$ & & $55 \quad \mathrm{p}$ & \\
\hline
\end{tabular}

From the analysis of regression coefficient of predictor variable (b, Beta), it was found that the results of T-test, F-test, and the constant for multiple regression equation predicting the decision to use loan services for Small and Medium Enterprise (SMEs) customers that have been selected into the regression equation, it was found;

Table 5. The analysis of regression coefficient of predictor the decision to use loan services for Small and Medium Enterprise (SMEs).

\begin{tabular}{|c|c|c|c|c|}
\hline \multirow{2}{*}{ Independent Variable } & \multicolumn{2}{|c|}{ Regression Coefficient } & \multirow[b]{2}{*}{$\mathbf{t}$} & \multirow{2}{*}{$\mathbf{P}$} \\
\hline & b & Beta & & \\
\hline Constant & 1.896 & & 12.033 & $.000^{* *}$ \\
\hline Personnel & .147 & .194 & 2.671 & $.008^{* *}$ \\
\hline Service Process & .360 & .432 & 5.958 & $.000^{* *}$ \\
\hline $\mathrm{R}=.597$ & $\operatorname{Adj~} R^{2}=.352$ & $\mathrm{SE}_{\mathrm{est}}=.45959$ & $.123 \mathrm{p}$ & \\
\hline
\end{tabular}

*refers to statistical significance at the level of .01 .

1. Service Process Variables (X7) were found with $B=.360$ showing that when the Service Process Factors (X7) are changed by 1 unit, the decision-making behavior of Small and Medium Enterprises customers (Y) will change to 360 units, under the condition that other variables must be stable.

2. Personnel Variables (X5) were found with $\mathrm{B}=.147$ showing that when the Personnel Factors (X7) are changed by 1 unit, it will cause the decision to choose the loan service for Small and Medium Enterprise customers (Y) to change by 147 units, under the condition that other variables must be stable. 
In conclusion, the variables that pose a significant effect on the decision to use loan services for Small and Medium Enterprise (SMEs) customers at the level of .01 are Service Process Factors $($ Beta $=.328)$, followed by Personnel Factors $($ Beta $=.244)$.

\section{Discussion}

From the analysis, it was found that the variable that significantly affect the decision to choose the loan service for small and medium enterprise (SMEs) customers at the level of .01 was the Service Process Factor $($ Beta $=.328)$, which can be interpreted that the service process factors have an influence on the decision to use loan services of Small and Medium Enterprises (SMEs) of Kasikorn Bank in the Northeastern region of Thailand.

The respondents specified that they paid importance to how the bank always checked the accuracy of a customer's loan application, that the bank provided convenient service and were quick to approve the loans, the bank had an accurate and reliable system, the bank managed loan applicators systematically and appropriately, the bank was accurate in recording the information for loan applications, the bank's documents were clear and easy to understand, the bank used modern equipment and up-to-date technology (such as internet banking services), and the bank's regulations and procedures in using services were not too complicated. All these are consistent with a study of [6].

Which explored the service marketing factors that affected the decision to use the loan services for export business customers of Bangkok Bank Public Company Limited in Mueang District, Chiang Mai Province. The results showed that the service marketing factors that found a high level of significance in selection of the services were the service process factors. This also corresponds with a study by (Murari, 2018). Which studied the marketing mix factors affecting the decision to choose the small business loan service from Kasikorn Bank of small entrepreneurs in Mueang Samut Sakhon District.

The study found that service process was the factor that most entrepreneurs paid a high level of importance to. They also prioritized sub-factors which were the use of an accurate and reliable system. Additionally, in [7]. Which explored factors affecting decisions to use the services of various banks in Cyprus, it was found that the most influential factor in choosing banking services was customers' confidence in a bank's management system.

Personnel factors: From the study, it was found that the service process was another factor that influenced the decision to use loan services of Small and Medium Enterprise (SMEs) customers of Kasikorn Bank in the Northeastern region of Thailand. The respondents were found to prioritize the care that loan managers gave to the customers; that they listened to opinions and customer feedback 90 wholeheartedly, bank staff had knowledge and expertise in providing business and loan consulting in a clear and reliable manner, loan managers were reliable and trustworthy, bank staff had a good personality and dressed appropriately for customer services, bank staff appeared extroverted and ready to be helpful, and loan managers could make decisions and solve problems for customers in a timely manner. These are consistent with the research of [8].

Which studied marketing mix factors affecting the decision to use housing loan services of customers of Asia Bank Public Company Limited in Mueang District, Chiang Mai Province. The results showed that the marketing mix factors that had an effect on the decision to use the housing loan service for customers of Asia Bank, Muang District, Chiang Mai Province were personnel factors which affected the decision to use loan services at a high level. This is consistent with the research of [9]. Which studied the service marketing mix factors influencing the decision to use housing loan services of the Government Savings Bank customers in the Mueang district, Chiang Mai Province. The results of the research showed that respondents gave importance to personnel factors as they were valued with a high level of importance. 
This is in line with the [10]. Which studied the service marketing factors that affected the decision to use the loan services for export business customers of Bangkok Bank Public Company Limited in Mueang District, Chiang Mai Province. The results showed that the service marketing factors found with a high level of significance in selection of the services were the personnel factors. This is also consistent with the work of [11].

Which studied factors affecting the decision of Small and Medium Enterprises entrepreneurs in using loan services of Krung Thai Bank Public Company Limited. In Mueang District, Chiang Mai Province. The results showed that the factors found to have the biggest effect on the decision of the SME entrepreneurs were the bank's personnel factors, followed by service process factors.

This also corresponds with the study of [12]. Which explored the factors affecting the decision to use personal loans of customers of Thai Bank Public Company Limited in Bangkok Metropolitan Region. The results revealed that marketing mix factor found to affect the decision to use personal loans of Thai personal loan customers in Bangkok Metropolitan Region was the service provided by bank employees service and how they provided fast and high-quality services.

In conclusion, the service process factors were found to influence the decision to use loan services of Small and Medium Enterprises (SMEs) of Kasikorn Bank in the Northeast region of Thailand at a high level. The entrepreneurs also agreed that how the bank regularly verified the correction of customers' loan request, how the bank also provided convenient service, and that the bank was quick to approve the loans were factors that most affect their decision to choose the loan services.

Therefore, banks should have an accurate and convenient loan approval process as it is the process expected to have the most reliable process with the least errors.

\section{References}

1. M. Suryakumar, T. Thirunavukkarasu, M. Nabi, Factors Contributing to MSME Entrepreneurs Level of Satisfaction on Banking Services (2019)

2. Office of Small and Medium Enterprises Promotion, Gross Domestic Product of Thai SMEs (2018) https://www.nationthailand.com

3. Kasikorn Bank (Public Company) Limited, K SME Care (2018) http://www.ksmecare.com/AboutUs.aspx

4. D. Ushakov, I. Elokhova, E. Kozonogova, International Journal of Ecological Economics and Statistics 38(2) (2017)

5. M. Usman, M. Shafiq, M. Savino, Z. Rashid, M.I. Yehya, A.A Naqvi, M. Menanno, IFAC-PapersOnLine 52(13), 2032-2037 (2019)

6. D. Tsuruta, The quarterly review of economics and finance 55, 40-52 (2015)

7. A. Mukhtar, H. Iman, H. Ashiq, R. Amjad, H. Nasar, Journal of Marketing and Management 2(1), 94-111 (2014)

8. A.S. Kakkattuchali, Studies in Indian place names 40(3), 5471-5490 (2020)

9. A.M. Adams, M. Bashiru, I.A. Abdulai, Journal of Social Science Studies 3(2), 217 (2016)

10. A. Amoah-Mensah, Customer satisfaction in the banking industry: a comparative study of Ghana and Spain (Universitat de Girona, 2011)

11. A. Suvittawat, Journal of Economic \& Management Perspectives 9(4), 21 (2015)

12. S. Thongpoon, Journal of Humanities and Social Sciences 36(2), 70-83 (2016) 